\title{
COMENTARIO AL AUTO DE LA AUDIENCIA PROVINCIAL DE ISLAS BALEARES (SECCIÓN 4a) NÚM. 54/2018, DE 10 DE ABRIL. UN APUNTE SOBRE LA PRUEBA DEL DERECHO EXTRANJERO EN UN PROCEDIMIENTO DE MEDIDAS CAUTELARES
}

\author{
AUDIENCIA PROVINCIAL (COURT OF APPEALS) OF THE \\ BALEARIC ISLANDS, 4TH SECTION. COMMENTARY TO \\ THE JUDICIAL DECREE 54/2018 OF APRIL 10TH, 2018. \\ NOTE TO THE PROOF OF FOREIGN LAW IN A PROCEDURE \\ REGARDING PRECAUTIONARY MEASURES.
}

\author{
Unai BeLINTXON MARTIN \\ Profesor Ayudante Doctor \\ Universidad Pública de Navarra
}

Recibido: 14.01.2019 / Aceptado: 25.01.2019

DOI: https://doi.org/10.20318/cdt.2019.4640

\begin{abstract}
Resumen: Interposición de Recurso de Apelación frente a Auto de instancia que deniega el establecimiento de medida cautelar (anotación preventiva de demanda) con la finalidad de evitar la enajenación de la vivienda conyugal tras la disolución del matrimonio por uno de los cónyuges y que impone el abono de las costas procesales al solicitante de la medida.

Palabras clave: disolución del matrimonio, costas procesales, medida cautelar, enajenación de vivienda conyugal, aplicación de Derecho extranjero, prueba del Derecho extranjero.

Abstract: Bringing an appeal against the judicial decree that denies the establishment of precautionary measures (provisional record of the claim) aiming at the avoidance of the marital property sale after the dissolution of marriage and declares the imposition of the court costs to its petitioner.

Keywords: dissolution of marriage, court costs, precautionary measures, marital property sale, the application of foreign law, proof of foreign law.

Sumario: I. Consideración preliminar. II. Hechos. III. Cuestiones controvertidas. IV. Un apunte sobre Derecho internacional privado. 1. Disolución del vínculo matrimonial. 2. Régimen económico matrimonial. 3. Prueba del Derecho extranjero. V. Consideración final.
\end{abstract}

\section{Consideración preliminar}

1. El 10 de abril de 2018, la Sección $4^{\text {a }}$ de la Audiencia Provincial de Islas Baleares estimó mediante Auto núm. 54/2018 un recurso de apelación surgido en procedimiento de medidas cautelares ante el Juzgado de Violencia sobre la mujer número 1 de Palma en el que de forma concreta se solicitaba la anotación preventiva de demanda reconvencional promovida en procedimiento de divorcio contencio- 
so por parte del esposo. La finalidad de tal solicitud de medida cautelar era evitar la enajenación de la vivienda conyugal por parte de la esposa (quién aparece como única titular registral de la citada finca). El Juzgado de Violencia sobre la mujer desestimó la solicitud de tal medida cautelar e impuso las costas procesales al solicitante.

2. Indicado lo anterior, el presente comentario tiene por objeto una vez expuestos los hechos acaecidos, analizar las cuestiones más controvertidas y su posible incidencia sobre nuestra disciplina de Derecho internacional privado.

\section{Hechos}

3. A la luz de los antecedentes expuestos en el Auto núm. 54/2018 de la Audiencia Provincial de Islas Baleares, concluimos que a la interposición de denuncia/querella por violencia de género por parte de la esposa se acompañó posteriormente demanda de divorcio ante el Juzgado correspondiente de Primera Instancia de Palma, quién mediante Auto se inhibió en favor del Juzgado de Violencia sobre la mujer número 1 de la propia Palma con la remisión de los autos correspondientes. Una vez ubicados los autos en este último Juzgado, la representación procesal del esposo contestó en tiempo y forma a la demanda de divorcio interpuesta y planteó demanda reconvencional a la que acompañó solicitud de adopción de medida cautelar consistente en anotación preventiva de la demanda sobre bien inmueble (el domicilio conyugal).

4. La citada medida cautelar fue admitida a trámite, y tras la vista preceptiva en pieza separada al procedimiento principal, la petición fue resuelta mediante Auto en sentido desestimatorio y se impusieron las costas del proceso a la parte promotora de la medida (el esposo).

5. Expuesto lo anterior es necesario subrayar que la pretensión de la medida cautelar solicitada por el esposo tenía por objeto evitar la enajenación del inmueble conyugal que constaba en el registro inscrito únicamente a nombre de la esposa. Esto es así debido a que el esposo insistió en que la propiedad constase única y exclusivamente a nombre de la esposa para evitar la posibilidad de que sus hijos, de un matrimonio anterior, pudieran reclamar la propiedad tras su fallecimiento. Parece pues advertirse que la argucia o estratagema jurídica diseñada por el esposo para con sus descendientes se vuelve ahora en su contra. El esposo pretende revertir tal situación ante el Juzgado de Violencia sobre la mujer número 1 de Palma reclamando que el bien inmueble sea calificado y/o considerado como bien matrimonial en aplicación de Derecho inglés. Con tal objetivo presenta informe de jurisconsulto inglés.

6. De la presentación en el procedimiento del citado informe del jurisconsulto inglés con la finalidad de convencer al Juzgador que el domicilio conyugal debe quedar sujeto y/o sometido al principio de reparto, parece poder desprenderse que los esposos ostentan la nacionalidad inglesa.

7. El Juzgador de instancia basa su decisión de desestimación de la medida cautelar solicitada en dos líneas de argumentación: 1) La primera línea de desestimación se centra en la ausencia de "fumus boni iuris". Entiende el Juzgador de instancia que frente a la titularidad formal del inmueble el esposo en todo caso tendría "[...] una mera expectativa conforme a cierta interpretación del Derecho inglés, según el informe del jurisconsulto presentado; expectativa cuya estructura y contenido material no parece la típica de los derechos reales. [...]", y en su caso la anotación solicitada únicamente cabría en aquellos supuestos en los que "[...] el éxito de la acción pudiera alterar el estado jurídico acreditado en el Registro, lo cual no sería el caso, por más que el inmueble de autos llegase a considerarse conforme al derecho inglés un "bien matrimonial", puesto que no se ha ejercitado con anterioridad ninguna acción dirigida a la modificación de la titularidad preexistente; siendo que pretender ahora sostener la cotitularidad desde el momento de la adquisición del bien en el año 2003 (sin perjuicio de lo que se resuelva de fondo en el pleito principal por razones diferentes o aplicación de normas de reparto de bienes entre cónyuges conforme al Derecho inglés) resulta contrario al principio general del Derecho que prohíbe beneficiarse de la propia 
actuación contraria al mismo, cuál sería el caso al afirmarse que se es propietario o copropietario del inmueble pero que no se figura como tal para ocultarlo a ciertos terceros (herederos hijos de un matrimonio anterior, a quienes se perjudica en beneficio de un titular o cotitular aparente) y luego se reclama que se reconozca esa titularidad o cotitularidad propia ab initio pero sin ejercitar acción que contravenga aquella simulación relativa (o, acaso, otro negocio subyacente indirecto, por ejemplo, una donación encubierta de parte del valor del bien) [...]."; y 2) La segunda línea en la argumentación de desestimación pivotaría en torno al "periculum in mora", considerando el Juzgador de instancia que la esposa "[...] ha explicado que es residente en Mallorca desde antes de contraer matrimonio [...], ha expresado su voluntad de continuar viviendo aqui, satisfacer la hipoteca y no tener intención de vender la vivienda de autos [...]. A ello se suma la falta de acreditación de cualquier dato externo sobre gestiones de venta o anuncio de la misma a través de cualquier canal ordinario (inmobiliaria, internet) que sugiera lo contrario.".

8. Cabe por otro lado aclarar que mediante el recurso de apelación interpuesto por la representación procesal del esposo únicamente se recurre ante la Audiencia Provincial el pronunciamiento sobre la imposición de costas al solicitante de las medidas, al considerar la parte recurrente que el criterio del vencimiento del artículo 394 en combinación con lo dispuesto por el 736.1, ambos de nuestra norma procesal interna ${ }^{1}$, debía en este caso haber sido atemperado.

9. Considera la Audiencia Provincial que en este caso, conscientes de que las medidas cautelares se fundan en una situación de apariencia de buen derecho y de potencial riesgo, las apariencias que constan en autos a pesar de no ser bastantes para justificar la adopción de la medida cautelar solicitada, podrían eventualmente serlo para entender que la causa analizada no merece pronunciamiento en costas. Por lo que el tribunal provincial estima el recuro interpuesto por el esposo al entender que el caso presenta ciertas dudas de hecho y de derecho de relevancia suficiente, a pesar de la inadmisión de la petición de medidas provisionales, para no hacer pronunciamiento en costas.

\section{Cuestiones controvertidas}

10. Descritos los hechos del caso se va hacer mención a ciertas cuestiones que a pesar de su indeterminación por ausencia de datos fácticos y descripción de los hechos, merecen subrayarse y valorar por su posible hipotética incidencia sobre nuestra disciplina de Derecho internacional privado.

\section{Posible ausencia de activación de los mecanismos de Derecho internacional privado}

11. De lo expuesto en el Auto analizado parece reflejarse que pudiera existir en el caso concreto un elemento de extranjería -matrimonio entre dos sujetos de nacionalidad británica sometidos al derecho inglés-. Advierto, "parece", pues no se puede concretar tal cuestión de lo descrito y dictaminado en el Auto de la Audiencia Provincial. No obstante no es menos cierto que tanto el Auto de la Audiencia en el párrafo cuatro del Fundamento de Derecho Segundo, como en la copia de la parte del Auto desestimatorio del Juzgado de Instancia que se reproduce en el Fundamento de Derecho Primero del propio Auto de la Audiencia Provincial analizado, se hace expresa referencia a un informe de un jurisconsulto inglés que acompaña a la solicitud de medida provisional en instancia por parte del esposo. Cuestión que nos lleva a entrever la existencia en este supuesto de cuanto menos un elemento de extranjería lo que implica la obligación de aplicar las normas de Derecho internacional privado.

12. Siendo así esto, es ciertamente poco ortodoxo que tanto el Auto del Juzgador de Instancia como el Auto de la Audiencia Provincial, a pesar de referirse ambos a una cuestión suscitada en pieza separada a la controversia principal, vengan a sustanciar la aplicación del Derecho extranjero mediante la siguiente valoración:

${ }^{1}$ Ley 1/2000, de 7 de enero, de Enjuiciamiento Civil. BOE n 7 de 08 de Enero de 2000. 
[...] Así las cosas, en el supuesto enjuiciado, el propio auto de primera instancia da muestras de que existían indicios del fumus boni iuris e indicios, si no prueba bastante, del periculum in mora. En cuanto al primero, en atención al hecho de que potencialmente hay que aplicar al caso el Derecho extranjero (de siempre compleja interpretación transfronteriza e informado, a favor de las tesis actoras, en el informe pericial del jurisconsulto británico), el propio auto, como hemos visto, expone con relación al "principio de reparto" (que se explica en el propio informe y que podría favorecer los derechos del actor-apelante sobre el inmueble), que "..., frente a la titularidad formal del inmueble el Sr. Nazario tendría, todo lo más, una mera expectativa conforme a cierta interpretación del Derecho inglés, ...".Es decir, en la propia resolución de instancia no se descarta alguna expectativa del actor. Y, en cuanto al periculum in mora, si bien el auto lo termina negando, sin embargo, reconoce expresamente que $\mathrm{D}^{\mathrm{a}}$ Angustia ha cambiado de opinión, y que, antes de la fecha de la demanda, había expresado su voluntad de venta del inmueble. En dicho sentido se pronuncia la resolución hoy apelada cuando afirma que, frente a lo alegado por la representación del Sr. Nazario , la Sra. Angustia ha explicado que es residente en Mallorca desde antes de contraer matrimonio con el Sr. Nazario , $\mathrm{y}^{\prime \prime} .$. ha expresado su voluntad de continuar viviendo aquí, satisfacer la hipoteca y no tener intención de vender la vivienda de autos; matizando que su manifestación de voluntad anterior en sentido contrario fue en junio de 2016, antes de la interposición de la demanda de divorcio por ella formulada.".

13. En efecto, se desconoce (aunque de los pronunciamientos citados parece que no es así), si el Juzgador de Instancia en el procedimiento principal ha tenido en consideración los citados elementos de internacionalidad a la hora de concretar cuestiones relacionadas con la concreción de la competencia judicial internacional y la determinación de la ley aplicable a la disolución del vínculo matrimonial y al régimen económico matrimonial, y por otro, las normas convencionales aplicables a la prueba del Derecho extranjero.

\section{Un apunte sobre Derecho internacional privado}

14. A pesar de no ser objeto del presente Auto las cuestiones apuntadas, pues éste únicamente se refiere a la estimación del recurso de apelación frente a la imposición de costas a la parte solicitante de las tratadas medidas cautelares en el Juzgado de Instancia. No es menos cierto que la determinación de dichas cuestiones parece haber pasado desapercibida tanto para la Audiencia como para el Juzgado de Instancia y exigen ser dilucidadas de una manera ajustada a nuestra disciplina del Derecho.

\section{Disolución del vínculo matrimonial}

15. Para la primera de las cuestiones planteadas, y en los casos en los que el Juzgado conocedor del asunto en primera instancia fuere el Juzgado de primera instancia correspondiese, y de acuerdo a la información facilitada en el caso, los tribunales españoles sí tendrían competencia judicial internacional según el Reglamento (CE) 2201/2003, de 27 de noviembre (Bruselas II bis) ${ }^{2}$, toda vez que, la última residencia habitual común de los cónyuges se localizaba en España (Mallorca) y la demandante continuaba viviendo allí en el momento de presentación de la demanda (3.1). En efecto, de lo expuesto debe concluirse que el tribunal de primera instancia ostentaría competencia judicial internacional para resolver sobre la disolución del vínculo matrimonial.

16. Para la segunda cuestión planteada, debemos subrayar que la ley aplicable al divorcio y la separación judicial viene normativizada en el Reglamento 1259/2010, de 20 de noviembre (Roma III) 3 . De esta manera a la luz de los datos reflejados en el Auto, y para el caso de que los cónyuges no hubiesen elegido la ley aplicable al divorcio según lo dispuesto por el artículo 5 del Reglamento Roma III, el De-

\footnotetext{
${ }^{2}$ Reglamento (CE) no 2201/2003 del Consejo de 27 de noviembre de 2003 relativo a la competencia, el reconocimiento y la ejecución de resoluciones judiciales en materia matrimonial y de responsabilidad parental, por el que se deroga el Reglamento (CE) $n^{\circ} 1347 / 2000$. DOUE L 338/1 de 23 de diciembre de 2003.

${ }^{3}$ Reglamento (UE) n ${ }^{\circ}$ 1259/2010 del Consejo de 20 de diciembre de 2010 por el que se establece una cooperación reforzada en el ámbito de la ley aplicable al divorcio y a la separación judicial. DOUE L 338/1 de 29 de diciembre de 2010.
} 
recho aplicable vendrá determinado por el artículo 8 del propio Reglamento Roma III. En consecuencia, conscientes de que la interposición de denuncia/querella ante el Juzgado de Violencia Sobre la Mujer conlleva la activación de una serie de protocolos y medidas de seguridad para la evitación de riesgos sobre la integridad física de la víctima, y conscientes también de la consiguiente interposición de demanda de divorcio por la esposa, en defecto de ley elegida por las partes entendemos que en este caso sería de aplicación lo dispuesto en el apartado b del citado artículo 8 (entendemos además que la demanda se presentó en plazo inferior a un año desde que cesó la residencia de los cónyuges debido a la fecha del Auto de inhibición del Juzgado de Primera Instancia número 3 de Palma en favor del Juzgado de Violencia sobre la mujer de la misma ciudad -23.09.2016-), por lo que sería aplicable el Derecho español al divorcio.

\section{Régimen económico matrimonial}

17. Tras el análisis de la disolución del vínculo matrimonial, debemos plantearnos los efectos jurídicos relacionados con la disolución y liquidación del régimen económico matrimonial. De esta manera, y a pesar de la inequívoca constancia registral de la propiedad de la finca en favor de la esposa, creemos interesante plantear si los tribunales españoles tendrían competencia para conocer de las cuestiones sobre el régimen económico matrimonial y la determinación de la ley aplicable a la misma cuestión.

18. En materia de competencia judicial internacional, y así lo será hasta el 29 de enero de 2019 con la entrada en vigor del Reglamento (UE) 2016/1103 del Consejo, de 24 de junio de $2016^{4}$, por el que se establece una cooperación reforzada en el ámbito de la competencia, la ley aplicable, el reconocimiento y la ejecución de resoluciones en materia de regímenes económicos matrimoniales ${ }^{5}$, debemos acudir al artículo 22 quater c) de la Ley Orgánica del Poder Judicial ${ }^{6}$ (LOPJ) para concretar la competencia judicial internacional y al artículo 9.2 del Código Civil $^{7}(\mathrm{Cc})$ para la determinación de la ley aplicable.

19. En lo que respecta al artículo 22 quater c) los tribunales competentes serán los españoles cuando ambos cónyuges posean residencia habitual en España al tiempo de la interposición de la demanda o cuando hayan tenido en España su última residencia habitual y uno de ellos resida allí. Sin duda del auto se desprende que el matrimonio tuvo su última residencia habitual en España y la demandante sigue aun residiendo allí.

20. Por otro lado, en cuanto a la ley aplicable, y realizando un ejercicio hipotético de que los cónyuges no celebraron capitulaciones matrimoniales, la cuestión tendrá que regirse por el artículo 9.2 del Cc. Un precepto que nos ofrece como primer punto de conexión la nacionalidad común de los cónyuges. Por lo que a la luz de lo expuesto en este caso sería de aplicación la ley inglesa.

\section{Prueba del Derecho extranjero}

21. Finalmente y debido a las referencias realizadas al Derecho inglés tanto por el Auto de Instancia desestimatorio de las medidas cautelares solicitadas como en el Auto de la Audiencia Provincial estimatorio del recurso y la declaración de no haber pronunciamiento en cuanto a las costas devengadas, es necesario realizar una crítica a la manera de solventar la invocación de la aplicación del Derecho

\footnotetext{
${ }^{4}$ DOUE L 183/1 de 8 de julio de 2016.

${ }_{5}^{5}$ Para obtener una buena visión en su conjunto sobre el Reglamento 2016/1103 relativo a los regímenes económico matrimoniales, donde se analiza en concreto el ámbito de aplicación, las normas de competencia judicial internacional, de ley aplicable y de reconocimiento y ejecución de resoluciones judiciales y aceptación y ejecución de documentos públicos y transacciones judiciales contenidas en dicho instrumento, entre otros, véase P. QuinZÁ REDONDO, "La unificación -fragmentada- del derecho internacional privado de la unión europea en materia de régimen económico matrimonial: El reglamento 2016/1103", Revista General de Derecho Europeo, $\mathrm{n}^{\circ} 41,2017$, pp. 180-222. Véase de igual forma sobre la necesidad de la armonización del Régimen económico matrimonial en la UE: P. QuINZÁ REDONDO, "La armonización y unificación del régimen económico matrimonial en la Unión Europea: nuevos desafíos y oportunidades", Revista chilena de derecho, Vol. 43, n 2, 2016, pp. 619-642.

${ }^{6}$ Ley Orgánica 6/1985, de 1 de julio, del Poder Judicial. BOE de 02 de Julio de 1985. BOE de 02 de Julio de 1985.

${ }^{7}$ GACETA de 25 de Julio de 1889.
} 
inglés mediante el informe de jurisconsulto inglés pues parece advertirse que en el procedimiento principal se ha realizado este mismo análisis y parece reflejar, cuanto menos, cierta ligereza al proyectar la siguiente conclusión respecto a la propiedad del domicilio conyugal: "frente a la titularidad formal del inmueble el Señor [...] tendría, todo lo más, una mera expectativa conforme a cierta interpretación del Derecho inglés".

22. Parece cuanto menos que el Juzgado de Instancia en el asunto principal primero, y el juzgado conocedor de la solicitud de medida cautelar después, ante la existencia de un elemento de internacionalidad de estas características, debiera haberse detenido para el análisis de la cuestión siguiendo los cauces y los mecanismos puestos a disposición por el Derecho internacional privado en un intento de averiguación de lo esgrimido y argumentado por la parte que presenta el informe del jurisconsulto inglés para justificar la solicitud de anotación preventiva de demanda reconvencional con la finalidad de evitar una hipotética enajenación del que fue el domicilio conyugal del matrimonio.

23. De esta manera, nos encontramos por un lado ante la necesidad de probar el contenido y demás extremos relativos al Derecho extranjero cuando éste debe ser aplicado por las autoridades jurisdiccionales españolas, y por otro, ante la necesidad de concretar el régimen jurídico de dicha prueba. En efecto, cabe entrar a valorar la adecuación del medio de prueba utilizado por la parte recurrente. Sin duda éste debe calificarse de un medio de prueba relativo, sobre todo si tenemos en consideración las dudas que los propios magistrados de la Audiencia reflejan en el Auto (en el que se reproducen las dudas y valoraciones del Juzgador de instancia) en relación a la argumentación esgrimida en el citado informe del jurisconsulto inglés.

24. En materia de prueba del Derecho extranjero y para el ordenamiento jurídico español es necesario reseñar la coexistencia de diversos cuerpos legales que regulan la cuestión. De esta manera, debe recordarse por un lado el carácter imperativo de la norma de conflicto establecida por el artículo 12.6 del Cc. Por otro, lo dispuesto por un artículo 281.2 de la Ley de Enjuiciamiento Civil sobre el que pivotan las cuestiones clave de la prueba del Derecho extranjero. Y finalmente los artículos 33 a 36 de la Ley de Cooperación Jurídica Internacional en Materia Civil ${ }^{8}$.

25. De lo expuesto en el artículo 281.2 de la LEC sobre el Derecho extranjero debe concluirse que éste debe probarse en cuanto a su vigencia y contenido, una cuestión siempre compleja de dilucidar y que a la vista de lo acontecido y de los errores reflejados en el informe de jurisconsulto inglés no se ha conseguido. En efecto, el artículo 281.2 requiere cuanto menos que: 1) El Derecho extranjero se pruebe; 2) Que se pruebe la vigencia y el contenido de tal Derecho extranjero; 3) La regla general contenida en el artículo 282 LEC requiere que la iniciativa de la actividad probatoria se active a instancia de parte (sin obviar la potestad del tribunal para utilizar los medios de averiguación que estime oportunos); y 4) Que se distinga claramente entre Derecho extranjero y los hechos de carácter procesal ${ }^{9}$.

26. La prueba del Derecho extranjero debe calificarse como una cuestión procesal. Advertido esto es evidente que ni el citado artículo 281.2 de la LEC, ni los artículos 33 a 36 de la Ley de Cooperación Jurídica Internacional en Materia Civil concretan los medios de prueba que pueden utilizarse con la finalidad de probar el Derecho extranjero. Una consciente laguna jurídica promovida por el legislador que permite cierto margen de libertad en cuanto a los medios probatorios a utilizar. Pruebas periciales y/o pruebas documentales son los recursos más habituales, y ciertamente la utilización de documentos públicos, declaración de testigos-peritos y los dictámenes proyectan cierta idoneidad para probar el Derecho extranjero ${ }^{10}$.

\footnotetext{
${ }^{8}$ Ley 29/2015, de 30 de julio, de cooperación jurídica internacional en materia civil. BOE $\mathrm{n}^{\mathrm{o}} 182$ de 31 de Julio de 2015.

9 A.L. Calvo Caravaca y J. Carrascosa González, Derecho internacional privado, vol. I, Granada, Comares, 2018, p. 546.

${ }^{10}$ Sobre la idoneidad del dictamen de jurisconsultos como fuente de prueba, entre otros: Derecho procesal civil internacional. Litigación internacional. M. VIRGós SORIANo y F.J. GarcimarTín Alférez, Derecho procesal civil internacional. Litigación internacional, Cizur Menor, Thomson Civitas, p. 531.
} 
27. Claro está, el juzgador y/o tribunal correspondiente tendrá que decidir sobre la admisión de la prueba propuesta, es decir valorará la fuerza probatoria que pueda desprenderse de los medios utilizados (contenido y vigencia) según las reglas de la sana crítica, tal y como indica el artículo 33.2 de la Ley de Cooperación Jurídica Internacional. Y desde luego, con los medios de prueba utilizados las partes tienen que convencer al tribunal del contenido del Derecho extranjero.

28. Por otro lado, respecto a los informes o dictámenes, que es precisamente el medio de prueba utilizado por el esposo en la solicitud de medida cautelar en instancia (informe de jurisconsulto inglés), debe indicarse que estos según lo preceptuado por el artículo 33.4 de la Ley de Cooperación Jurídica Internacional no ostentarán carácter vinculante para los órganos jurisdiccionales españoles.

29. A pesar de que el AAP de Islas Baleares analizado se pronuncie únicamente sobre la estimación del recurso de apelación interpuesto frente a la imposición de costas en instancia dónde se solicitaron la aplicación de medidas cautelares, y en consecuencia para revertir las costas impuestas a la parte recurrente la Audiencia Provincial haya articulado su argumentación en torno a los conceptos de "fumus boni iuris" y "periculum in mora" y haya apreciado la posibilidad de atemperar el criterio de vencimiento (artículos 394 y 736.1 LEC), no es menos cierto que el análisis del Auto comentado requiere del estudio y valoración de los argumentos esgrimidos en el Auto de desestimación de instancia que da pie al recurso de apelación interpuesto ante la Audiencia Provincial.

30. En definitiva, del Auto de instancia se desprende que el juzgador, y así lo suscribe el tribunal superior, entiende que no queda acreditada la consideración y/o calificación del bien inmueble que aparece registrado únicamente a nombre de la esposa como bien matrimonial según lo reflejado en el informe del jurisconsulto inglés. No obstante, si bien es cierto que un informe de un jurisconsulto inglés puede no ser en este caso concreto (más aun teniendo en cuenta que éste presenta innumerables errores en la concreción de los hechos y en los datos fácticos a tener en consideración) la mejor herramienta para probar que según el Derecho inglés dicho bien inmueble pudiera ser considerado bien matrimonial, no es menos cierto que el Juzgado de Instancia solventa la cuestión con cierta despreocupación tal y como hemos reseñado anteriormente. El juzgador de instancia se apoya a su vez en la inexistencia o ausencia de acción previa por parte del esposo dirigida a la modificación de la titularidad preexistente. Lo que no obsta para que el Juzgado hubiere utilizando su potestad como tribunal para utilizar los medios de averiguación que estimase oportunos en materia de prueba de Derecho extranjero.

31. Finalmente, a modo de reflexión debemos plantear si la intrínseca flexibilidad que refleja el sistema español en materia de prueba del Derecho extranjero requiere para un procedimiento cautelar que dicha flexibilidad sea aún mayor. En efecto, este tipo de procedimientos cautelares que deben sustanciarse con rapidez exigen de una mayor flexibilidad de los medios de prueba utilizados por las partes en sede de valoración por parte del Juzgado o Tribunal. Es más, incluso podríamos plantearnos si los mecanismos de prueba del Derecho extranjero de los que dispone de oficio el Juzgado o Tribunal son los más adecuados para ello en un procedimiento de estas características. Esto es lo que precisamente pasaría con la activación del Convenio de Londres de 1968 para cuestiones de prueba e información del Derecho extranjero ${ }^{11}$ en un procedimiento de medidas cautelares. A nuestro juicio no tendría sentido su activación debido a la necesaria rapidez y/o inmediatez exigida por esta clase de procedimientos. No obstante, éste no obsta para que el citado Convenio sea una adecuada herramienta jurídica a invocar y a activar en un procedimiento ordinario.

32. En esencia podemos concluir que activar mecanismos de estas características no sería lo más adecuado en procedimientos cautelares que requieren una mayor flexibilidad en materia de prueba de Derecho extranjero debido a su urgencia, rapidez e inmediatez. Desde luego para este tipo de casos el intencionado descuido del legislador en la regulación de los medios probatorios a utilizar es incluso positivo.

${ }^{11}$ Convenio Europeo de 7 de junio 1968, al que se adhirió España por instrumento de 2 de octubre de 1973. Convenio Europeo acerca de la información sobre el derecho extranjero, hecho en Londres. BOE nº 249, de 7 de octubre de 1974. 


\section{Consideración final}

33. A pesar de que el objeto del Auto analizado versa únicamente sobre la estimación del recurso de apelación interpuesto frente a la imposición de costas en procedimiento cautelar de instancia, su análisis nos ha permitido valorar la disolución del vínculo matrimonial al presentar ambos cónyuges nacionalidad inglesa, los efectos jurídicos relacionados con la disolución y liquidación del régimen económico matrimonial y la forma en la que se solventa en dicho procedimiento cautelar en instancia la invocación de la aplicación del Derecho inglés.

34. De lo estudiado en materia de prueba de Derecho extranjero puede concluirse que tanto el Juzgado de Instancia, como la Audiencia Provincial, debieran haberse detenido de forma más diligente en el análisis de la cuestión relativa a la prueba del Derecho extranjero en el ordenamiento jurídico español. Desde luego, la consciente laguna jurídica promovida por el legislador que potencia cierto margen de libertad en materia de medios probatorios a utilizar, les hubiera permitido concluir que la inherente flexibilidad que refleja el sistema español en materia de prueba del Derecho extranjero requiere para un procedimiento cautelar que dicha flexibilidad sea aún mayor.

35. Es evidente que este tipo de procedimientos cautelares que deben sustanciarse con mayor urgencia y celeridad requieren una mayor flexibilidad de los medios de prueba, y en consecuencia, una diligente ponderación en la valoración de la prueba aportada sobre el Derecho extranjero por parte de los órganos jurisdicciones que responda a tal urgencia e inmediatez. Además, no debe obviarse que de oficio el Juzgado o Tribunal tiene la potestad de activar los mecanismos que considere más oportunos para probar tal Derecho extranjero, su vigencia y contenido, dentro de lo razonable para un procedimiento de tales características. 